\title{
Traslado en ambulancia, alargamiento de tiempo inevitable en cada sesión de diálisis
}

\section{Begoña Capillas Echevarria - $\mathbf{M}^{\mathrm{a}}$ Soledad Diez de Baldeón Herrero - Arantza Arrausi Larrea} Estibaliz Etura Ule - Maite González Manjon - Miren Echavarri Escribano

Unidad de Hemodiálisis - Hospital Santiago Apóstol .Vitoria-Gasteiz

\section{Sra. Directora:}

Los pacientes que precisan de diálisis necesitan, aparte de las horas correspondientes en cada caso, unas horas extras en los traslados desde su domicilio y a su domicilio, debido a varios factores que se suman.

Por una parte la escasez de recursos, la dotación de ambulancias es escasa y hay que compartirlas con el resto de centros de la provincia. Y por otra la accesibilidad desde sus puntos de origen, localidades distantes al centro de diálisis y poblaciones pertenecientes a otras provincias, que por kilometraje se dializan en nuestra unidad. En la misma atendemos a cuarenta pacientes, de los cuales treinta y tres precisan los servicios de ambulancia y solo siete son autónomos. En general, los que lo requieren son personas de edad, con patologías añadidas y que necesitan ayuda parcial o total para sus traslados.

Hemos querido saber la media de horas que precisa cada paciente por cada sesión de diálisis y como in-

\author{
Correspondencia: \\ Begoña Capillas Echevarria \\ Unidad de Hemodiálisis \\ Hospital Santiago Apóstol \\ C/Olaguibel, 29 \\ 01004-Vitoria-Gasteiz \\ bcapillas@hsan.osakidetza.net
}

terfiere ese tiempo en su vida cotidiana, dado que consume más de un tercio del día en cada sesión.

Para esto se han recogido datos de tiempos de 33 pacientes que precisan de ambulancia desde la hora que tienen previsto salir de su domicilio hasta la hora que regresan a casa (figura 1 ). De estos, 11 pacientes tienen su residencia en diferentes localidades de la provincia y anexos, y 12 viven en la misma localidad donde se realiza la diálisis.

\section{DISTRIBUCIÓN DE PACIENTES SEGÚN DESTINO}

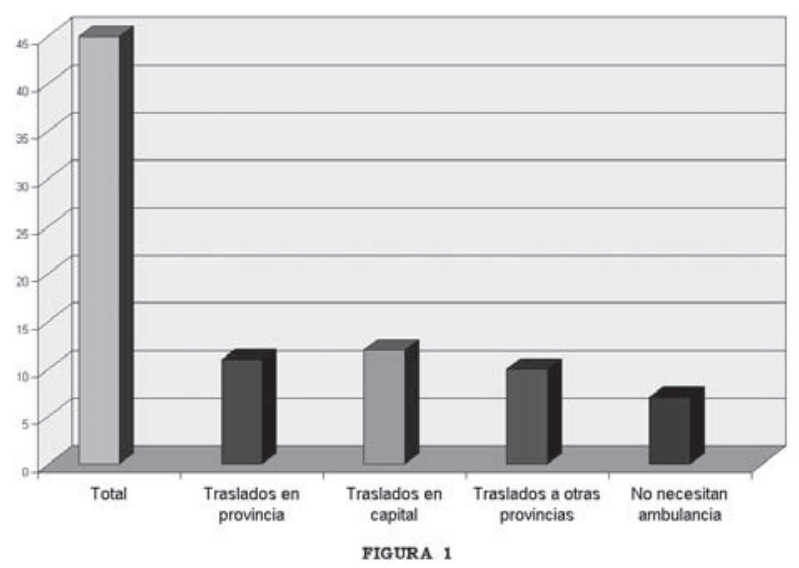

Para la recogida de datos hemos utilizado una encuesta donde se recogían los siguientes puntos (figura 2): 


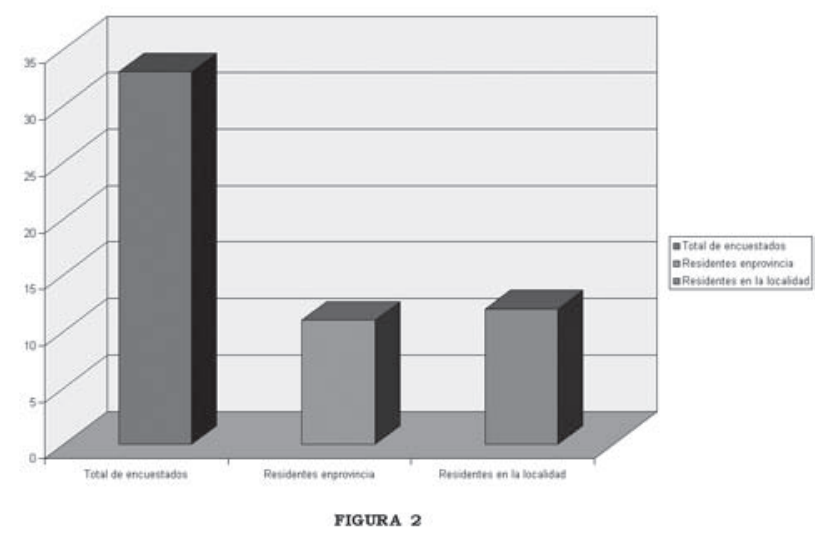

- Localidad

- Hora prevista de salida de su domicilio. Todos los pacientes tienen una hora en la que la ambulancia tiene que recogerlos y a partir de esa hora ellos están preparados y esperando.

- Hora de recogida de su domicilio. Hora en que llega la ambulancia para realizar el traslado.

- Horas estipuladas de diálisis.

- Hora prevista de salida de la unidad de hemodiálisis. A veces se retrasa, bien por tiempo añadido al tratamiento o por la llegada tardía del transporte.

- Hora de llegada a su domicilio.
Se ha realizado una encuesta de satisfacción con tres preguntas:

- Si consideran que hay retraso de ambulancias

- Si están satisfechos con el servicio

- Si ven alterada su forma de vida por el tiempo de espera de ambulancias

- Comentarios

De los resultados obtenidos cabe destacar:

- Respecto al tiempo. El tiempo medio que consumen los pacientes en sus traslados en ambulancia es de $2 \mathrm{~h}$. $30^{\prime}$ entre el viaje de ida y vuelta a sus domicilios, siendo el tiempo mínimo de 1 h. 40’ y el máximo de 5 h.

- Respecto a la encuesta.

a) El $60,6 \%$ considera que hay retrasos y el $39,4 \%$ considera que no

b) El $66,6 \%$ está satisfecho con el servicio de ambulancias, frente al $33,4 \%$ que opina que no

c) El $60,6 \%$ ve alterada su forma de vida, mientras que un $39,4 \%$ considera que no

d) El comentario más frecuente $(60 \%)$, coincide en lo que afecta a los horarios de comidas y sueño.

Ante estos resultados podemos concluir que el tiempo de diálisis se incrementa a casi el doble por la necesidad que existe de realizar sus traslados en ambulancia y que este hecho altera los hábitos de horarios de comidas y sueño de los pacientes. 